\title{
Recruitment, maturation, and spawning of Loligo forbesi Steenstrup (Cephalopoda: Loliginidae) in Irish waters
}

\author{
M. A. Collins, G. M. Burnell, and P. G. Rodhouse
}

Collins, M. A., Burnell, G. M., and Rodhouse, P. G. 1995. Recruitment, maturation, and spawning of Loligo forbesi Steenstrup (Cephalopoda: Loliginidae) in Irish waters. - ICES J. mar. Sci., 52: 127-137.

\begin{abstract}
A number of reproductive indices were compared with a subjective maturity scale for assessment of Loligo forbesi maturity. The ratio between nidamental gland length and mantle length corresponded well with female maturation, as did the ovary mass-soma mass and nidamental gland mass-soma mass ratios. For males, the ratio between spermatophoric complex mass and somatic mass was found to be the most suitable for maturity assessment. The timing of recruitment and maturation of L. forbesi in Irish waters was described from the size and maturity of squid in commercial landings in the south of Ireland during the years 1991-1993. Immature squid first appeared in commercial catches in July and August, and this represented the main period of recruitment. A second period of recruitment was apparent in December 1991, but was not identified in the 1992-1993 season. Mature females were present in the commercially exploited population between November and $\Lambda$ pril, with a small number also found in the summer. The abundance of egg masses was used to indicate timing of spawning. Egg masses recovered from the Cork coast indicated that peak spawning occurred during the winter months, but continued on a small scale for much of the year.
\end{abstract}

Key words: squid, Loligo forbesi, recruitment, maturation, reproduction, spawning.

Received 11 July 1994; accepted 19 September 1994.

M. A. Collins (present address: Zoology Department, University of Aberdeen, Tillydrone Avenue, Aberdeen AB9 2TN, Scotland) and G. M. Burnell: Zoology Department, University College, Cork, Ireland. P. G. Rodhouse: British Antarctic Survey, Natural Environmental Research Council, High Cross, Madingley Road. Cambridge CB3 OET, England.

\section{Introduction}

Thirty-two species of cephalopods have been recorded in Irish waters (Massy, 1928), of which only Loligo forbesi Steenstrup is currently of commercial interest. L. forbesi is found throughout the north-east Atlantic from west Africa to Norway, around the Azores and in the Mediterranean (Roper et al., 1984). In Irish waters it is usually caught as a by-catch in trawl fisheries, but is occasionally targeted during the autumn when it becomes most abundant. Despite recent investigations in Scottish waters (Lum-Kong et al., 1992; Boyle and Ngoile, 1993a, b; Pierce et al., in press; Boyle et al., in press), many aspects of the life cycle of $L$. forbesi are not fully understood, and in a widely distributed species such as $L$. forbesi the timing of life-cycle events may vary geographically (Voss, 1983).

The timing of recruitment, maturation, and spawning of $L$. forbesi has been described in Scottish waters (Lum-Kong et al., 1992; Boyle and Ngoile, 1993a, b;
Pierce et al., in press), in the English Channel (Holme, 1974), on the Faroe Bank (Gaard, 1987), and around the Azores (Martins, 1982); however, no data have been published for Irish waters. Around Britain the main recruitment is during the summer months, with peak spawning in the winter months (Holme, 1974; Lum-Kong et al., 1992; Pierce et al., in press). Holme (1974) also identificd a summer-spawning group, whilst Lum-Kong et al. (1992) suggested that in Scottish waters some spawning may continue sporadically throughout the year. A 1-year life cycle with terminal spawning has been proposed for L. forbesi (Holme, 1974) and is supported by evidence from putative daily statolith growth increment counts (Collins et al, in press); however, growth rates in culture experiments suggest a longer life span around the British Isles (Hanlon et al., 1989).

The assessment of maturity in cephalopods is important in recognizing spawning populations (Voss, 1983) and in understanding the mechanisms of control in the process of sexual maturation (Mangold, 1987). A variety 
of scales and reproductive indices have been proposed for maturity assessment and extensivcly reviewed by Juanico (1983). Maturity can be assessed either by a subjective, qualitative method (e.g. Lipinski, 1979) or by quantitative objective methods using the ratio of the mass of one or more of the reproductive or accessory reproductive organs to body or somatic tissue mass (e.g. Macy, 1982). Different workers have applied different subjective scales to the same species, making accurate comparison of data difficult. Lipinski's universal scale (Lipinski, 1979) is probably the most widely used.

The present study investigates the timing of recruitment, maturation and spawning of L. forbesi in Irish waters using data from commercial samples, research cruise catches, and recovered egg masses, and compares the assessment of maturity by reproductive indices with Lipinski's universal maturity scale.

\section{Methods}

Monthly samples of the squid Loligo forbesi were obtained from commercial otter trawls from vessels from the ports of Dunmore East, Kilmore Quay, and Youghal (south-east Ireland). Exact details of gear and location of capture were not known, but most trawlers operate in the locality of their home port, and thus samples were likely to have come from the Celtic Sea and southern Irish Sea (ICES Areas VIIa and VIIg). The June 1992 sample was obtained from research trawls in the Celtic Sea on RV "Lough Beltra", using a Courlette 3 bridled butterfly trawl with $10-\mathrm{mm}$ cod-end liner. The samples in July and September 1992 and July and October 1993 were obtained from research cruises in the Irish Sea on RV "Lough Foyle", using a commercial rockhopper trawl with 20-mm cod-end liner. The samples from research cruises included some small animals that would not be caught by commercial gear, but unsexed squid $(<60 \mathrm{~mm})$ were not included. Additional samples were obtained from the ports of Killibegs (north-west Ireland) in August 1992 and Dingle (southwest Ireland) in February 1993. The Dingle sample was caught at approximately $400 \mathrm{~m}$ depth off the west coast (ICES Area VIIb), and the Killibegs sample came from the Rockall Bank (ICES Area VIb). Samples were not sorted and were assumed to be representative of the exploited squid population. Where possible, 200 individuals were obtained each month; however, during certain months, notably March-June, catches were small and samples difficult to obtain.

All samples were dissected while fresh. All squid in each sample were measured to the nearest $\mathrm{mm}$ dorsal mantle length (ML), sexed, weighed wet (to $0.01 \mathrm{~g}$ ), and assigned a maturity stage in accordance with Lipinski's universal scale (Lipinski, 1979). A sub-sample (minimum 50 animals) was taken for dissection of reproductive tissues. Terminology of the reproductive and accessory reproductive organs follows Juanico (1983).

In females the length of the nidamental glands (NGL) was measured in situ to the nearest $\mathrm{mm}$, and wet masses obtained (to the nearest $0.01 \mathrm{~g}$ ) for the reproductive and accessory reproductive structures, i.e. nidamental glands (NGM), ovary (OVM), oviduct (ODM), oviducal gland including oviducal opening (OGM), and accessory nidamental glands (ANGM).

In males, wet masses of the spermatophoric complex (SCM) and testis (TM) were obtained. Spermatophoric complex includes sperm duct, spermatophoric organ, spermatophoric duct, spermatophoric sac, and penis.

For the calculation of the reproductive indices for both males and females the mass of the somatic organs and tissue (SM) was used (SM = total body mass - mass of reproductive and accessory reproductive organs). The quantity $\mathrm{OM}$ is the sum of ovary mass (OVM) plus oviduct mass (ODM). RM is the total mass of all reproductive and accessory reproductive organs.

Egg mass records were obtained from three fishermen from an area off the County Cork coast between Cork and Youghal. The fishermen employed lobster pots and tangle nets with effort approximately constant throughout the year. Samples of egg masses were returned to the laboratory, hatched in a recirculating seawater system, and subsequently identified as $L$. forbesi from the descriptions of Segawa et al. (1988).

All statistical analyses were carried out using the Minitab statistical package (Ryan et al., 1985).

\section{Results}

\section{Timing of recruitment and maturation}

Commercial samples consisted almost entirely of L. forbesi, with occasional specimens of Todaropsis eblanae (Ball) and a single L. vulgaris (Lamarck). In all, 4663 L. forbesi were examined, of which 2404 were female $(51.5 \%)$ and 2259 were male $(48.5 \%)$. For each monthly sample the ratio of males to females was tested for deviations from the expected 1:1 ratio using the chi-squared test with Yates correction factor (Zar, 1984). Only 3 months showed a significant deviation $(p=0.05)$ from the 1:1 ratio. In January 1992 and April 1993 males were more numerous, whilst in August 1992 females dominated the sample.

Monthly length frequency distributions of male and female $L$. forbesi for the three seasons of sampling in the Celtic Sea are shown in Figures 1-3. Males clearly show greater variation in size than females. Monthly maturity of males and females are plotted for 1991-1993 (Fig. 4). Recruitment is identified by the appearance in commercial catches of smaller, less mature animals. In both years small, immature squid first appeared in commercial catches in July or August (Figs 1-4), and 

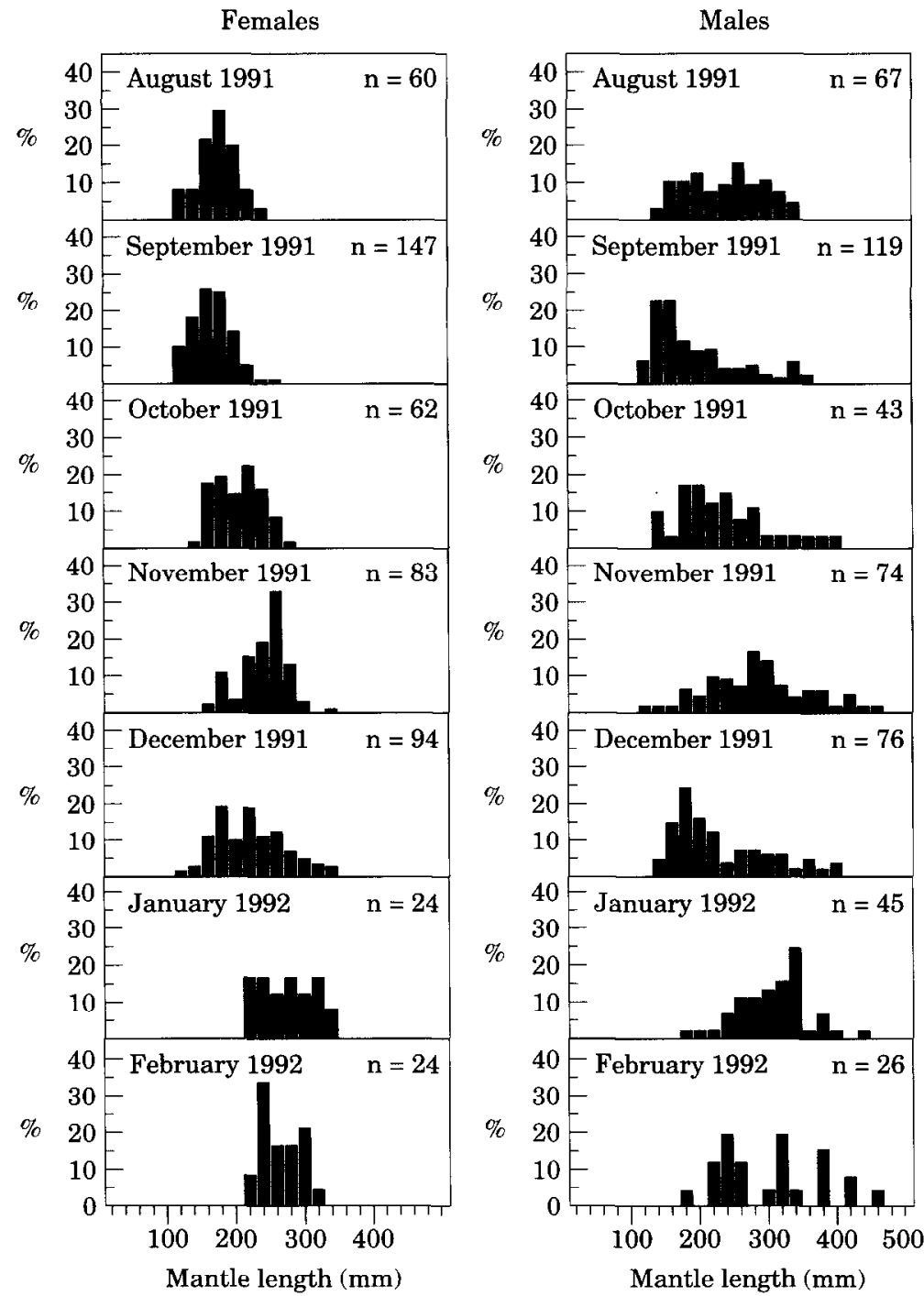

Figure 1. Length-frequency histograms of male and female Loligo forbesi for August 1991-February 1992 from commercial samples from the Celtic Sea.

this represented the main period of recruitment. In December 1991 a second period of recruitment to the fishery was identified (see Figs 1, 4) but no second recruitment was apparent in the 1992-1993 season.

Mature females (stages IV and V) were present from November until April, although in 1992 no samples were obtained between March and May. Two mature females were also found in June 1992. No immature females were found in samples from February to April. Mature males first appeared in October, slightly earlier than females, and small numbers of immature males remained in the population throughout the winter. Mature females were regularly found mated, with sperm stored in the buccal membrane. No spent animals were found, although two mature males in which the testis was greatly reduced were found in March 1993.

The sample obtained from the west coast in February 1993 comprised mature animals, caught at a greater depth $(400 \mathrm{~m})$ than is usual for $L$. forbesi. The sample from the Rockall Bank (August 1992) consisted of immature animals of a larger size than was caught in the Celtic and Irish Seas at this time.

The data indicate a single extended spawning season, beginning in November and possibly continuing until as late as June. From February catches in the Irish and Celtic Sea tended to be small, suggesting that spawning squid had migrated from the fishing grounds or had died. 


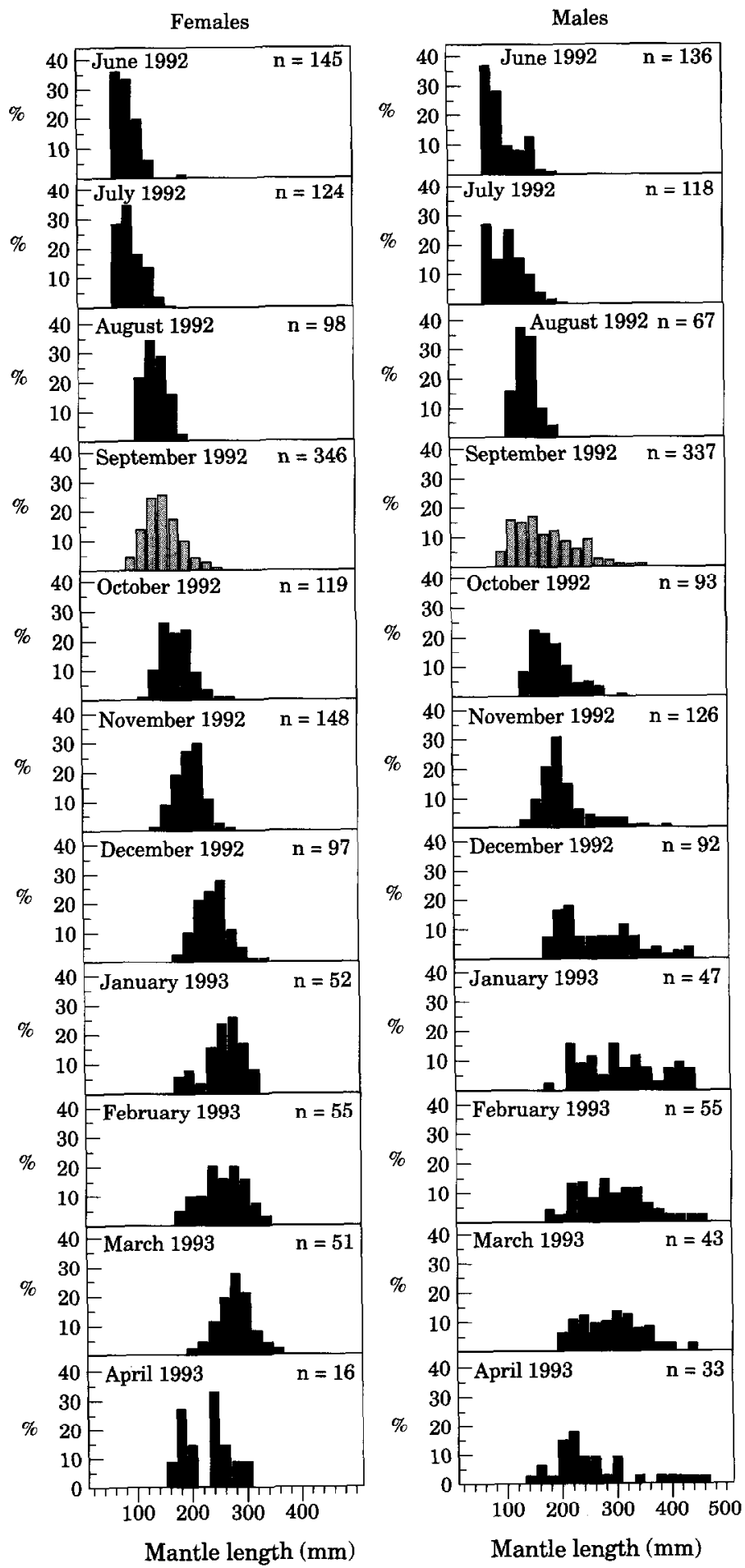

Figure 2. Length-frequency histograms of male and female Loligo forbesi for June 1992-April 1993 from commercial samples and research cruises in the Celtic Sea. The September sample (highlighted) came from a research cruise in the Irish Sea and small squid $(<60 \mathrm{~mm})$ have been excluded. 

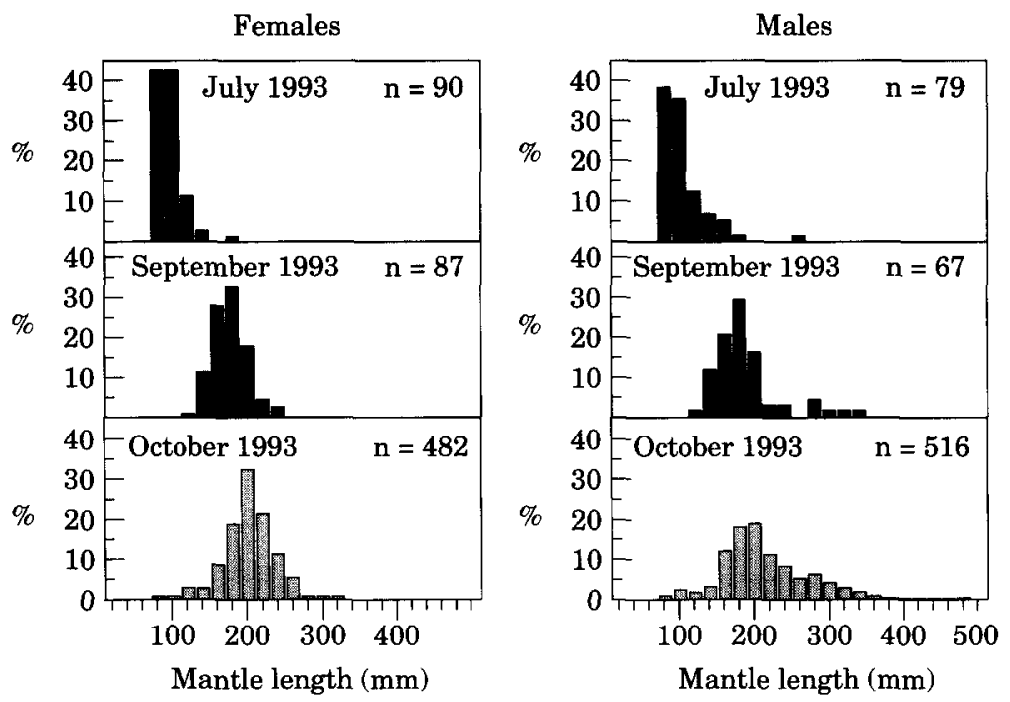

Figure 3. Length-frequency histograms of male and female Loligo forbesi for July-October 1993 from commercial samples and research cruises in the Celtic Sea. The October sample (highlighted) came from a research cruise in the Irish Sea and small squid $(<60 \mathrm{~mm})$ have been excluded.

\section{Comparison of maturity scale and reproductive indices}

Correlations of the reproductive indices with Lipinski's maturity scale (Lipinski, 1979) are given in Table 1 . The relationships are illustrated for selected indices as kite diagrams (Figs 5, 6). The kite diagrams express the percent frequency of values within each division of the maturity scale.

In the females NGL/ML, NGM/SM, OVM/SM, RM/SM, and OM/SM correlated well with Lipinski's maturity scale (Table 1). However, from the kite diagrams it can be seen that there was considerable overlap of the reproductive index values between the maturity stages, notably between stages IV and V. For males, SCM/SM produced the best correlation with Lipinski's maturity scale; but again there was considerable overlap between maturity stages, particularly stages IV and V. The TM/SM, SCM/RM, and SCM/TM ratios produced poor correlations with the maturity scale. Figure 7 shows the monthly changes in the reproductive index values (NGL/ML and OM/SM for females; SCW/SM for males), and these reflect the frequency of maturity stages shown in Figure 4.

\section{Egg mass data}

The average numbers of $L$. forbesi egg masses recovered in each calendar month from static fishing gear off the Cork coast during the period April 92-March 94 are detailed in Figure 8. In most instances egg masses were recovered from static gear laid on rock or hard substratum, away from trawling grounds. Large egg masses, comprised of 50-100 fingers of eggs, were common. The majority of egg masses were recovered during the months November-April, with a slight decline in January; small numbers of egg masses were also recovered during the summer months.

\section{Discussion}

\section{Assessment of maturity}

Maturity assessment using subjective, qualitative maturity scales such as that of Lipinski (1979) has certain advantages over the quantitative reproductive indices. Visual maturity scales are quick and relatively easy to use. They impose, however, unnatural discontinuity on the maturation process and may be subject to differing interpretations amongst workers. Reproductive indices provide a continuously varying assessment of maturity, which is clearly defined and comparable between studies. Male and female maturity scales are not directly comparable. In practical terms, female maturity is more important in assessing timing of spawning in loliginids, since males often mate with females that are not fully mature (Lum-Kong et al., 1992).

In this study, the ratios of NGL/ML, OM/SM, RM/SM, OVM/SM, and NGM/SM all correlated well with the female maturation process. NGL/ML is probably the most useful field index, since length measurements are simpler to obtain than weights. The comparatively poor correlations between maturity stages and reproductive indices in male $L$. forbesi are probably due in part to the two sizes at which maturity is attained (Boyle et al., in press; Collins, 1994). The 

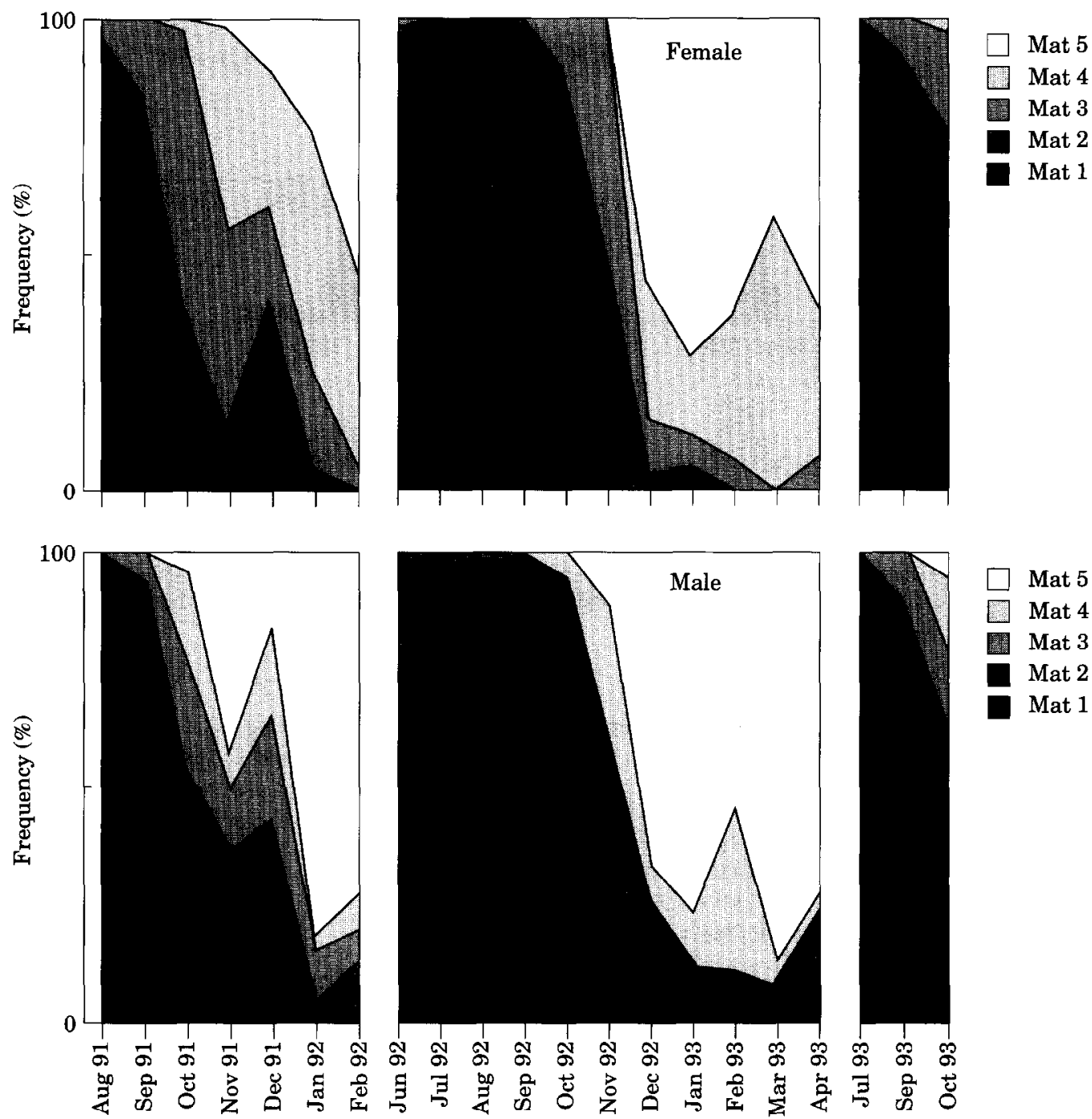

Month

Figure 4. Percent of each maturity stage in monthly samples, from the Celtic Sea, of male (above) and female Loligo forbesi.

ratio of SCM/SM correlated best with the maturity scale for male $L$. forbesi, and this index, or slight variations of it, have proved a useful measure of maturity in other studies (e.g. Macy, 1982; Boyle and Ngoile, 1993a). Depletion of the testis during the final stages of maturation and mating means that testis mass may not be useful in determining maturity in male loliginids. The overlap of reproductive index values between maturity stages IV and V of both sexes is probably due to the differences between these stages being purely qualitative. In females, the main difference between stages IV and V relates to the appearance of the eggs in the oviduct, whilst in males the structure of spermatophores in the spermatophoric sac distinguishes the stages.
Timing of recruitment, maturation and spawning

The problems associated with relying on commercially caught samples in a study such as this have been outlined by Lum-Kong et al. (1992); most importantly it is difficult to know to what extent samples provide a true reflection of the population.

In Irish waters the main recruitment of $L$. forbesi occurs in the summer, at a similar time and size to that described by Holme (1974) for the English Channel. The second period of recruitment in December 1991 may be equivalent to the weak November recruitment reported by Boyle and Ngoile (1993b) in Scottish waters. Boyle and Ngoile (1993b) and Pierce et al. (in press) reported 
Table 1. Correlations of reproductive indices with Lipinski's universal maturity scale for male and female Loligo forbesi.

\begin{tabular}{llrcc}
\hline & Maturity index & $\mathrm{n}$ & Correlation coefficient & $\mathrm{r}^{2}$ \\
\hline \multirow{2}{*}{ Males } & SCM/SM & 818 & 0.774 & 0.560 \\
& TM/SM & 818 & 0.555 & 0.308 \\
& RM/SM & 818 & 0.707 & 0.499 \\
& SCM/RM & 818 & -0.011 & 0.001 \\
Females & TM/SCM & 1135 & -0.160 & 0.026 \\
& NGL/ML & 571 & 0.887 & 0.787 \\
& NGM/SM & 571 & 0.908 & 0.824 \\
& OM/SM & 571 & 0.881 & 0.776 \\
& RM/SM & 571 & 0.864 & 0.746 \\
& OVM/SM & 631 & 0.884 & 0.781 \\
& ODM/OVM & & 0.293 & 0.085 \\
\hline
\end{tabular}
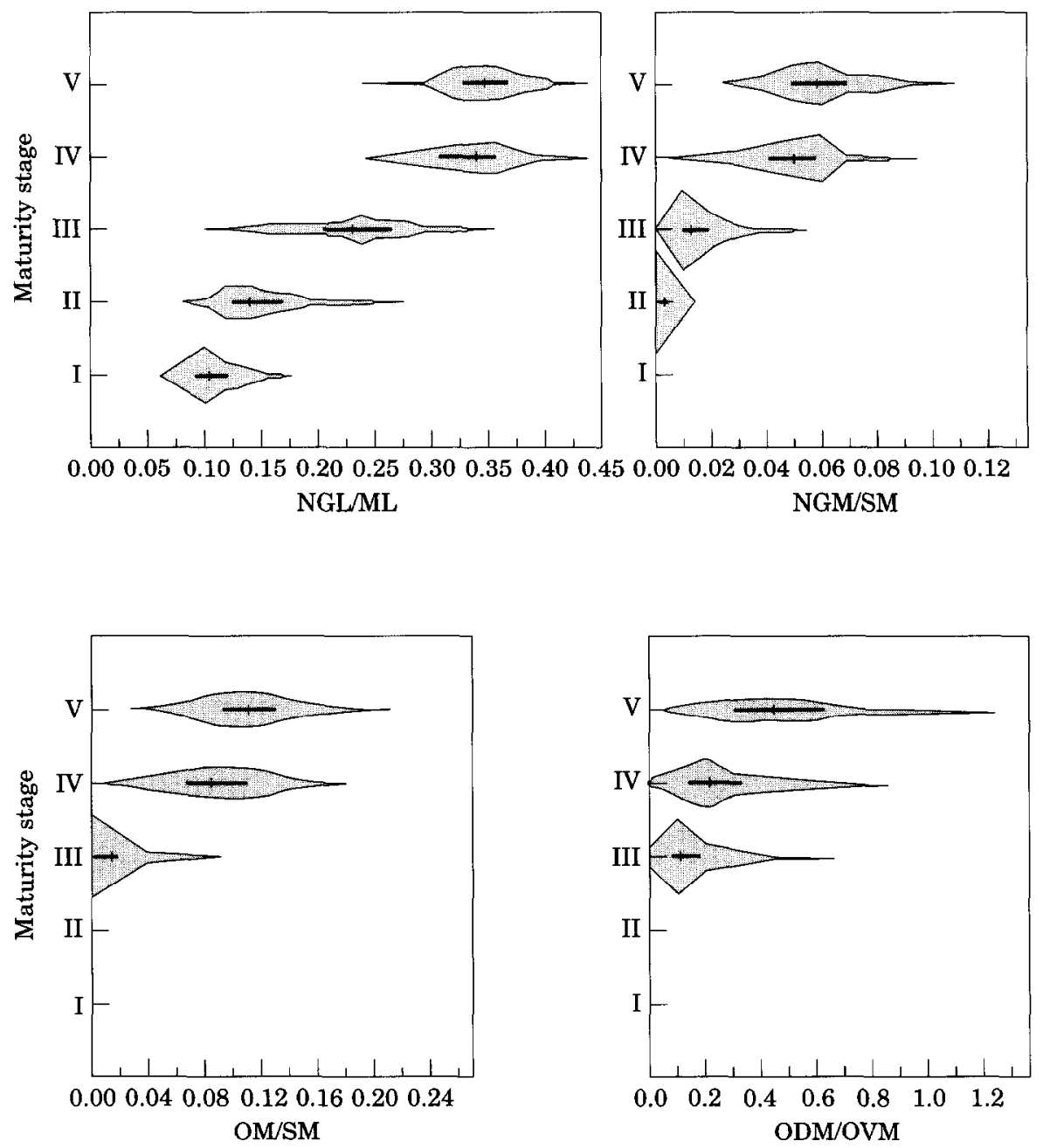

Figure 5. Kite diagrams of relationship between maturity stage (Lipinski, 1979) and reproductive indices for female Loligo forbesi. Vertical bars=mean; horizontal bars=interquartile range. 

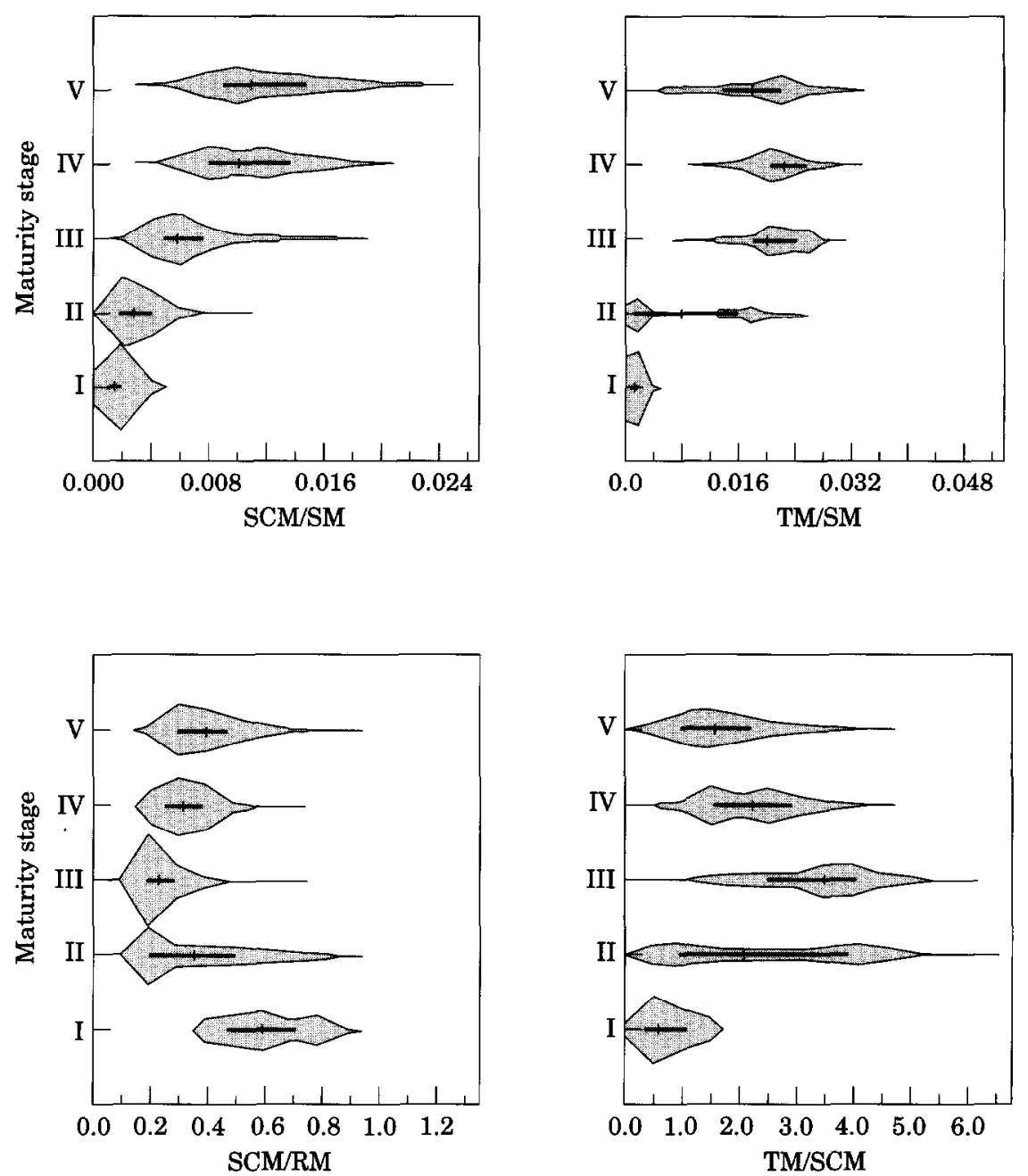

Figure 6. Kite diagrams of relationship between maturity stage (Lipinski, 1979) and reproductive indices for male Loligo forbesi. Vertical bars = mean; horizontal bars =interquartile range.

an April recruitment in Scottish waters, which probably contributed to the Rockall Bank fishery, but there was no evidence of recruitment at this time in the Irish or Celtic Seas.

It is evident from the maturity of commercial samples and egg mass data in this study that spawning of $L$. forbesi in the Irish and Celtic seas occurs primarily during the months November-April, with a peak in December, as in the English Channel (Holme, 1974). Peak spawning of $L$. forbesi is slightly later in Scottish waters (Lum-Kong et al., 1992; Boyle and Ngoile, 1993a; Pierce et al., in press) and later again on the Faroe Bank (Gaard, 1987). There may be a trend of later peaks in spawning activity with increased latitude. It is apparent, however, from the recovered egg masses that in Irish waters spawning continues at a reduced level throughout the late spring and early summer, but it should be noted that egg mass records were only collected from a small area of the Cork coast, and spawning may occur at other times in other areas. The peak in the proportion of mature females in the exploited population (January-April) and the peak in recovered egg masses (November-December) were not synchronous and it may be that, by January, the population has been rapidly depleted and so only small numbers of squid (all mature) remain. This is supported by commercial landings data, which show a considerable decline from December (Collins, 1994).

The evidence of this and other studies suggests that there are multiple spawning groups of $L$. forbesi in Irish and adjacent waters. The August recruits probably spawn in November-January, whilst the December 1991 recruits, and the mature squid caught off the west coast in February, probably spawn around April. Brierley (1992) reported a bimodal size structure in the $L$. forbesi populations around the Isle of Man, which provides 


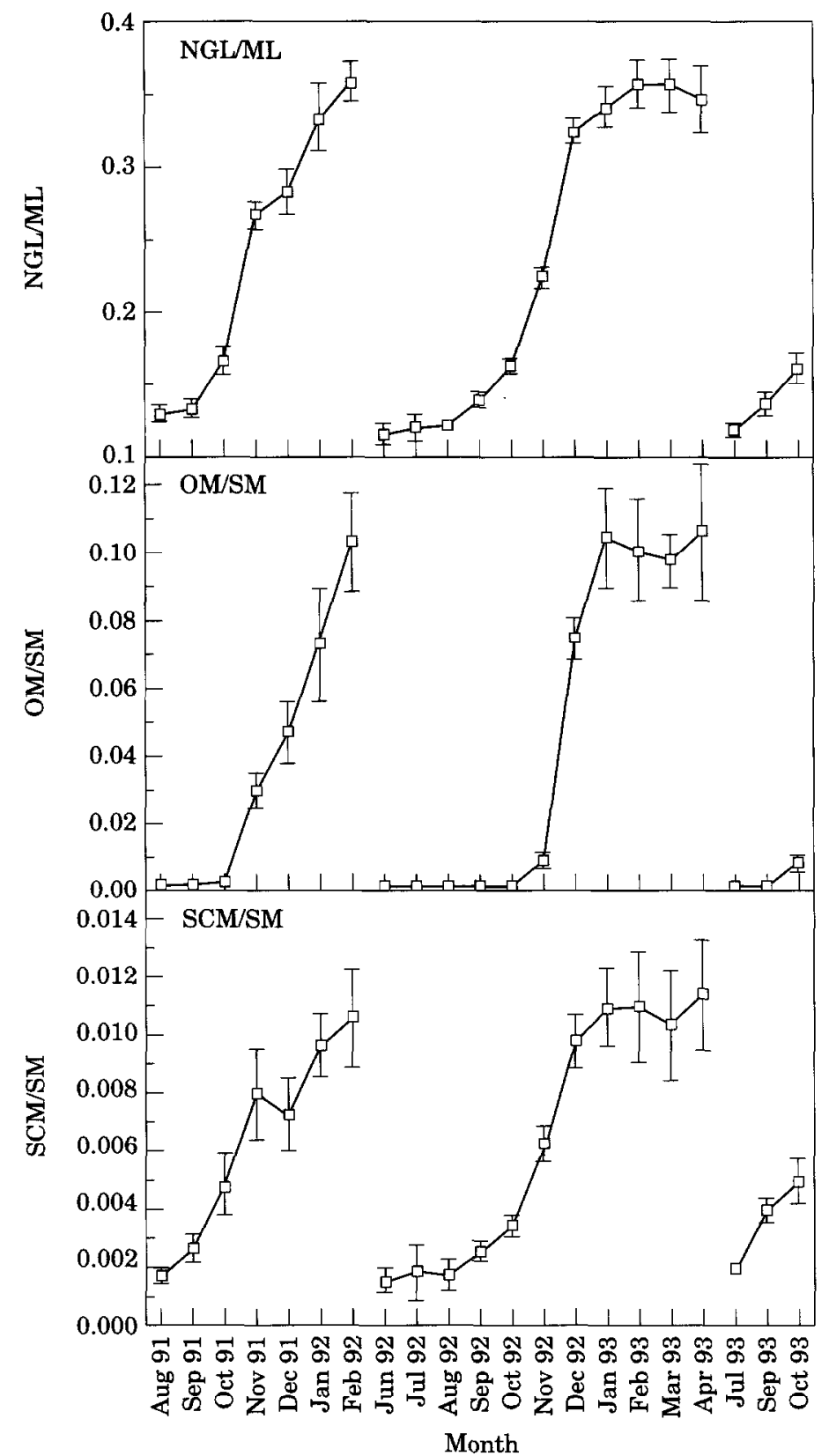

Figure 7. Monthly variation in mean values $( \pm 2 \mathrm{SE}$ ) of the female reproductive indices nidamental gland length/mantle length (NGL/ML) and oviduct + ovary mass/soma mass (OM/SM) and the male reproductive index spermatophoric complex mass/soma mass (SCM/SM) in Loligo forbesi from the Celtic Sea.

further evidence of a second cohort in Irish and adjacent waters. The Rockall Bank squid were suggested by Pierce et al. (in press) to be an additional offshore population of $L$. forbesi which recruits in April, appearing in the summer on the Rockall Bank and probably spawning in the autumn. Pierce et al. (in press) found mature animals on the Rockall Bank in October, but it is not known if spawning occurs there. Large quantities of
$L$ forbesi egg masses have been reported from the west coast of Ireland in September and October (K. Flannery, pers. comm.), and this may be the site of spawning for the Rockall population.

The absence of large squid during the summer, coupled with the lack of spent animals, supports the hypothesis that L. forbesi is semelparous, dying soon after spawning (Holme, 1974). From the results of 


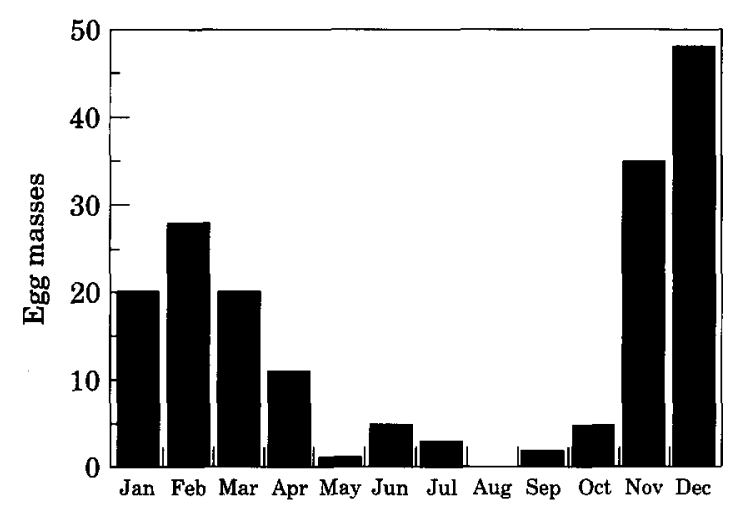

Month

Figure 8. Average numbers of Loligo forbesi egg masses recovered per month from the east Cork coast by three specific fishermen fishing at relatively constant effort.

culture experiments Hanlon et al. (1989) questioned whether L. forbesi was capable of growing rapidly enough to account for a 1-year life cycle in UK waters. However, the results of this study and others (Holme, 1974; Lum-Kong et al., 1992; Boyle and Ngoile, 1993a, b; Pierce et al., in press; Collins et al., in press) indicate that the life span of $L$. forbesi is unlikely to exceed 1 year.

\section{Spawning grounds}

Most egg masses were recovered from inshore areas $(10-50 \mathrm{~m})$ on hard substrata, but this may reflect the distribution of static fishing gear rather than the true distributions of egg masses. Other loliginids are also believed to spawn in inshore areas (e.g. McGowan, 1954; Hatfield et al., 1990; Sauer et al., 1992), though not necessarily on hard substrata. Mature animals were also found at depths of $400 \mathrm{~m}$, and on the Rockall Bank (Pierce et al., in press) and Lum-Kong et al. (1992) suggested that most spawning may occur offshore, but there is no direct evidence of this. The spawning areas of $L$. forbesi may be away from the trawling grounds, which may explain the lack of spent or partially spent females in commercial catches. Egg masses were often large and probably produced by a number of females. In some other loliginids the presence of egg masses is known to elicit spawning (Mangold, 1987), and large numbers of females may contribute to single large egg masses (McGowan, 1954; Sauer et al., 1992).

\section{Acknowledgements}

This work was partially funded by Bord Iascaigh Mhara. Thanks are due to Dave Neal, Kieran Healy, and Tony Hennessy for their help in collecting egg mass records. We also thank Paul Connolly (FRC), Mike Armstrong (DANI), Kevin Flanncry, Sean White, Mattie Burns, and the Fishermen's Co-ops at Kilmore Quay and Dunmore East for help in obtaining samples. Finally, thanks to Emma Hatfield, Peter Boyle, Ruth O'Riordan, Tom Cross, and one anonymous referee for their comments on the manuscript, and to the members of the ICES Study Group on Cephalopod Biology for many useful discussions.

\section{References}

Boyle, P. R., and Ngoile, M. A. K. 1993a. Assessment of maturity state and seasonality of reproduction in Loligo forbesi (Cephalopoda: Loliginidae) from Scottish waters. In Recent advances in cephalopod fisheries biology, pp. 37-48. Ed. by T. Okutani, R. K. O'Dor, and T. Kubodera. Tokai University Press, Tokyo. 752pp.

Boyle, P. R., and Ngoile, M. A. K. 1993b. Population variation and growth of Loligo forbesi (Cephalopoda: Loliginidae) from Scottish waters. In Recent advances in cephalopod fisheries biology, pp. 49-59. Ed. by T. Okutani, R. K. O'Dor, and T. Kubodera. Tokai University Press, Tokyo. 752pp.

Boyle, P. R., Pierce, G. J. and Hastie, L. C. In press. Flexible reproductive strategies in the squid Loligo forbesi. Marine Biology

Brierley, A. S. 1992. Aspects of genetic diversity and population structure in squid. Ph.D. thesis. University of Liverpool. $154 \mathrm{pp}$.

Collins, M. A. 1994. Biology of the squid Loligo forbesi Steenstrup in Irish waters. Ph.D. thesis. National University of Ireland. 182pp.

Collins, M. A., Burnell, G. M., and Rodhouse, P. G. In press. Age and growth of the squid Loligo forbesi (Cephalopoda: Loliginidae) in Irish waters. Journal of the Marine Biological Association of the UK.

Gaard, E. 1987. An investigation of the squid Loligo forbesi Steenstrup on Faroe Bank. ICES CM. 1987/K: 18, 9pp.

Hanlon, R. T., Yang, W. T., Turk, P. E., Lee, P. G., and Hixon, R. F. 1989. Laboratory culture and estimated life span of the eastern Atlantic squid Loligo forbesi Steenstrup, 1856 (Mollusca: Cephalopoda). Aquaculture and Fisheries Management, 20: 15-34.

Hatfield, E. M. C., Rodhouse, P. G., and Porebski, J. 1990. Demography and distribution of the Patagonian squid (Loligo gahi d'Orbigny) during the austral winter. Journal du Conseil International pour l'Exploration de la Mer, 46: 306-312.

Holme, N. A. 1974. The biology of the squid Loligo forbesi (Mollusca: Cephalopoda) in the Plymouth area. Journal of the Marine Biological Association of the UK, 54: 481-503.

Juanico, M. 1983. Squid maturity scales for population analysis. In Advances in assessment of world cephalopod resources. FAO Fisheries Technical Paper No. 231, pp. 341-378. Ed. by J. F. Caddy. FAO, Rome. 452pp.

Lipinski, M. R. 1979. Universal maturity scale for the commercially important squids (Cephalopoda: Teuthoidea). The results of the maturity classification of Illex illecebrosus (Le Sueur 1821) population for years 1973-1977. International Commission for Northwest Atlantic Fisheries Research Document. 79/II/38 Serial No. 5364. 40pp.

Lum-Kong, A., Pierce, G. J., and Yau, C. 1992. Timing of spawning and recruitment in Loligo forbesi (Cephalopoda: Loliginidae) in Scottish waters. Journal of the Marine Biological Association of the UK, 72: 301-311. 
McGowan, J. A. 1954. Observations on the sexual behaviour and spawning of the squid Loligo opalescens, at La Jolla, California. California Fish and Game, 40: 47-54.

Macy, W. K. 1982. Development and application of an objective method for classifying long-finned squid, Loligo pealei into sexual maturity stages. Fishery Bulletin, 80: 449-459.

Mangold, K. 1987. Reproduction. In Cephalopod life cycles, Vol. II. Comparative reviews, pp. 157-200. Ed. by P. R. Boyle. Academic Press, London. 441pp.

Martins, H. R. 1982. Biological studies of the exploited stock of Loligo forhesi (Mollusca: Cephalopoda) in the Azores. Journal of the Marine Biological Association of the UK, 62 : 799-808.

Massy, A. L. 1928. The Cephalopoda of the Irish coast. Proceedings of the Royal Irish Academy, 38 B: 25-37.

Pierce, G. J., Boyle, P. R., Hastie, L. C., and Key, L. In press. The life history of Loligo forbesi (Cephalopoda: Loliginidae) in Scottish waters. Fisheries Research.
Roper, C. F. E., Sweeney, M. J., and Nauen, C. E. 1984. FAO species catalogue, Vol. 3. Cephalopods of the world: An annotated and illustrated catalogue of species of interest to fisheries. FAO Fisheries Synopsis, No. 125. 277pp.

Ryan, B. F., Joiner, B. L., and Ryan, T. A. 1985. Minitab handbook. Duxbury Press, Boston. 379pp.

Sauer, W. H. H., Smale, M. J., and Lipinski, M. R. 1992. The location of spawning grounds, spawning and schooling behaviour of the squid Loligo vulgaris reynaudii (Cephalopoda: Myopsida) off the eastern Cape coast, South Africa. Marine Biology, 114: 97-107.

Segawa, S., Yang, W. T., Marthy, H. J. and Hanlon, R. T. 1988. Illustrated embryonic stages of the eastern Atlantic squid Lolign forhesi. The Veliger, 30: 230-243.

Voss, G. L. 1983. A review of cephalopod fisheries biology. Memoirs of the National Museum of Victoria, 44: 229-241.

Zar, J. H. 1984. Biostatistical analysis. Prentice Hall 718pp. 